Supporting Information

For

\title{
Proton-Coupled Electron Transfer in \\ Ruthenium(II)-Pterin Complexes: Formation of \\ Ruthenium-Coordinated Pterin Radicals and Their \\ Electronic Structures
}

Soushi Miyazaki, ${ }^{\dagger}$ Takahiko Kojima, ${ }^{*}{ }^{\dagger}$ Taisuke Sakamoto, ${ }^{\ddagger}$ Tetsuya Matsumoto,

Kei Ohkubo, ${ }^{\dagger}$ and Shunichi Fukuzumi ${ }^{*}{ }^{\dagger}$

Department of Material and Life Science, Graduate School of Engineering, Osaka University and SORST (JST), Suita, Osaka 565-0871, and Department of Chemistry, Faculty of Sciences, Kyushu University, 6-10-1 Hakozaki, Higashi-Ku, Fukuoka 812-8581, Japan

E-mail: kojima@chem.eng.osaka-u.ac.jp (T. K.) and fukuzumi@ chem.eng.osaka-u.ac.jp (S. F.)

${ }^{\dagger}$ Department of Material and Life Science, Osaka University and SORST (JST).

${ }^{*}$ Department of Chemistry, Kyushu University. 
(a)

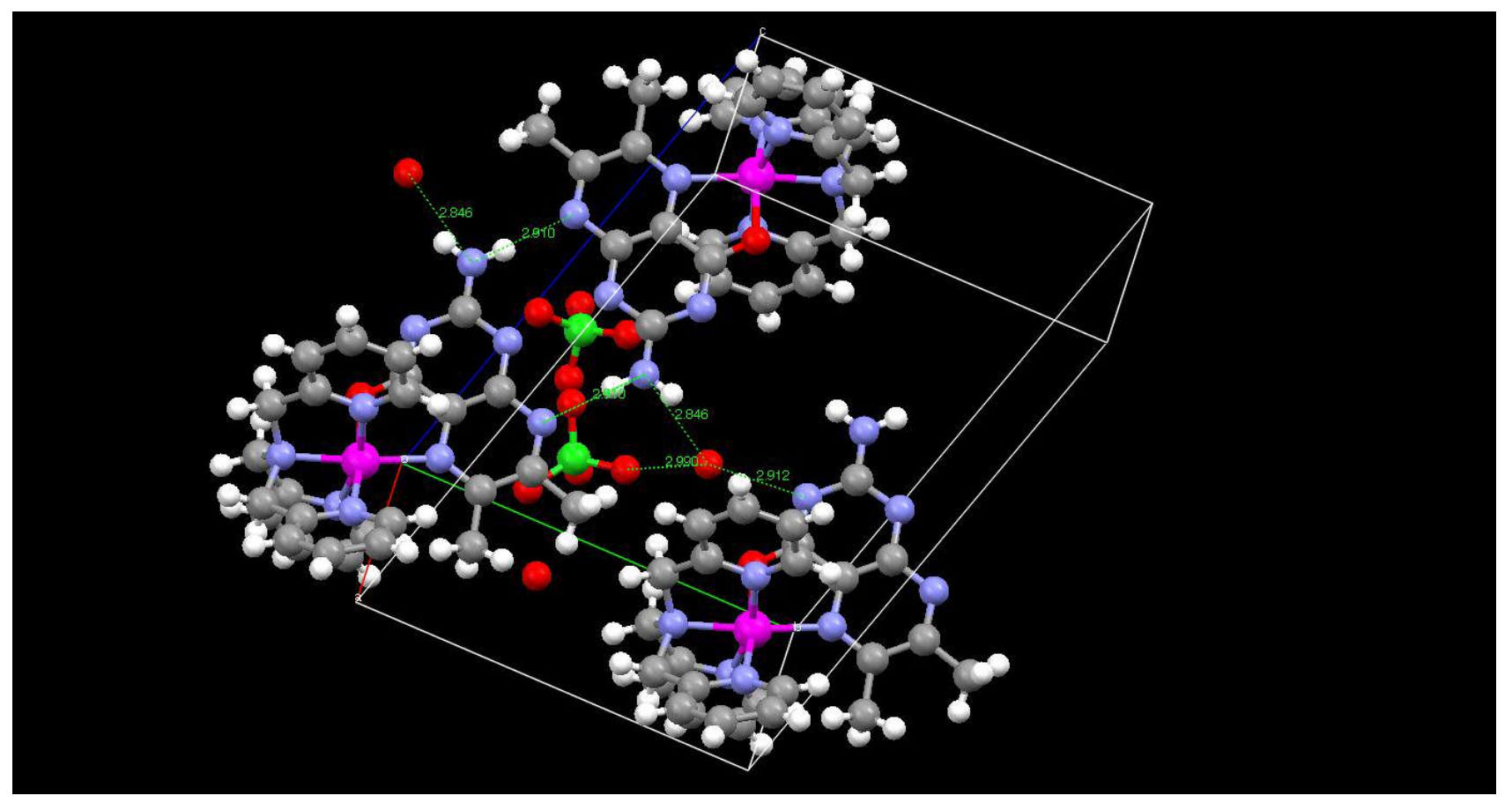

(b)

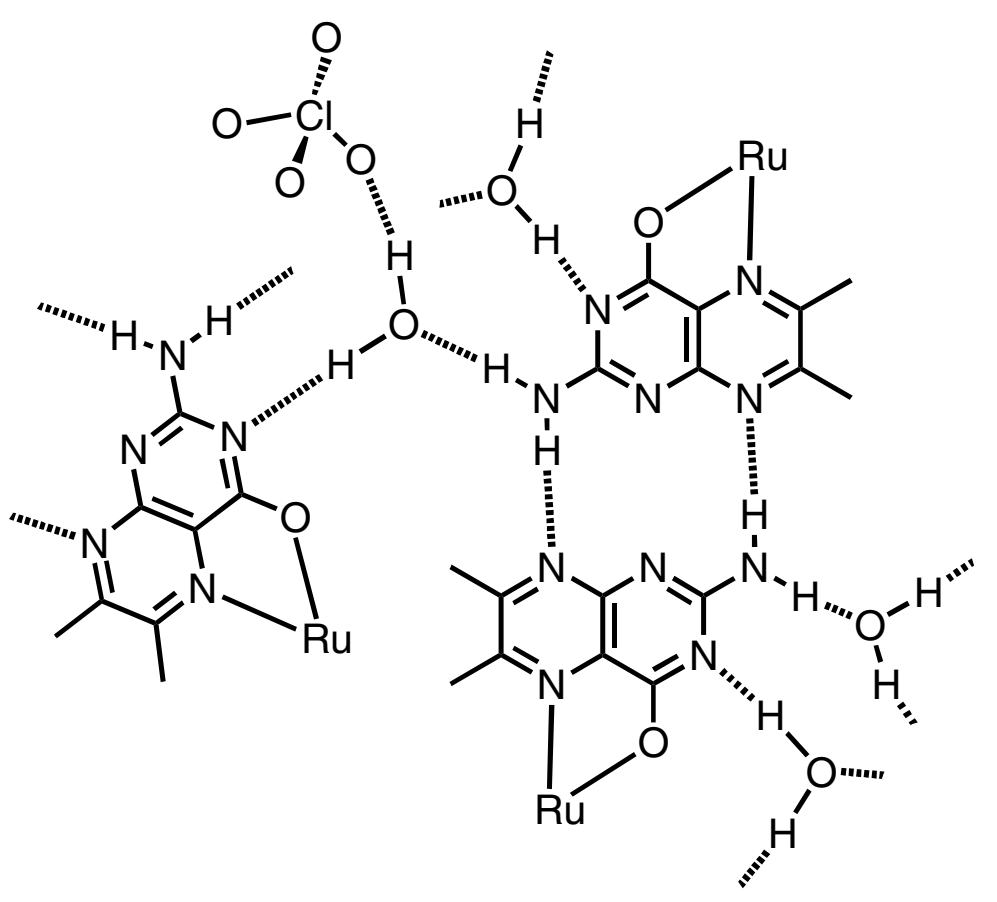

Figure S1. (a) Hydrogen bonding network in the crystal of 3. Gray, carbon; white, hydrogen; blue, nitrogen; red, oxygen; light green, chlorine; pink, ruthenium. (b) A schematic description of the hydrogen bonding network. 

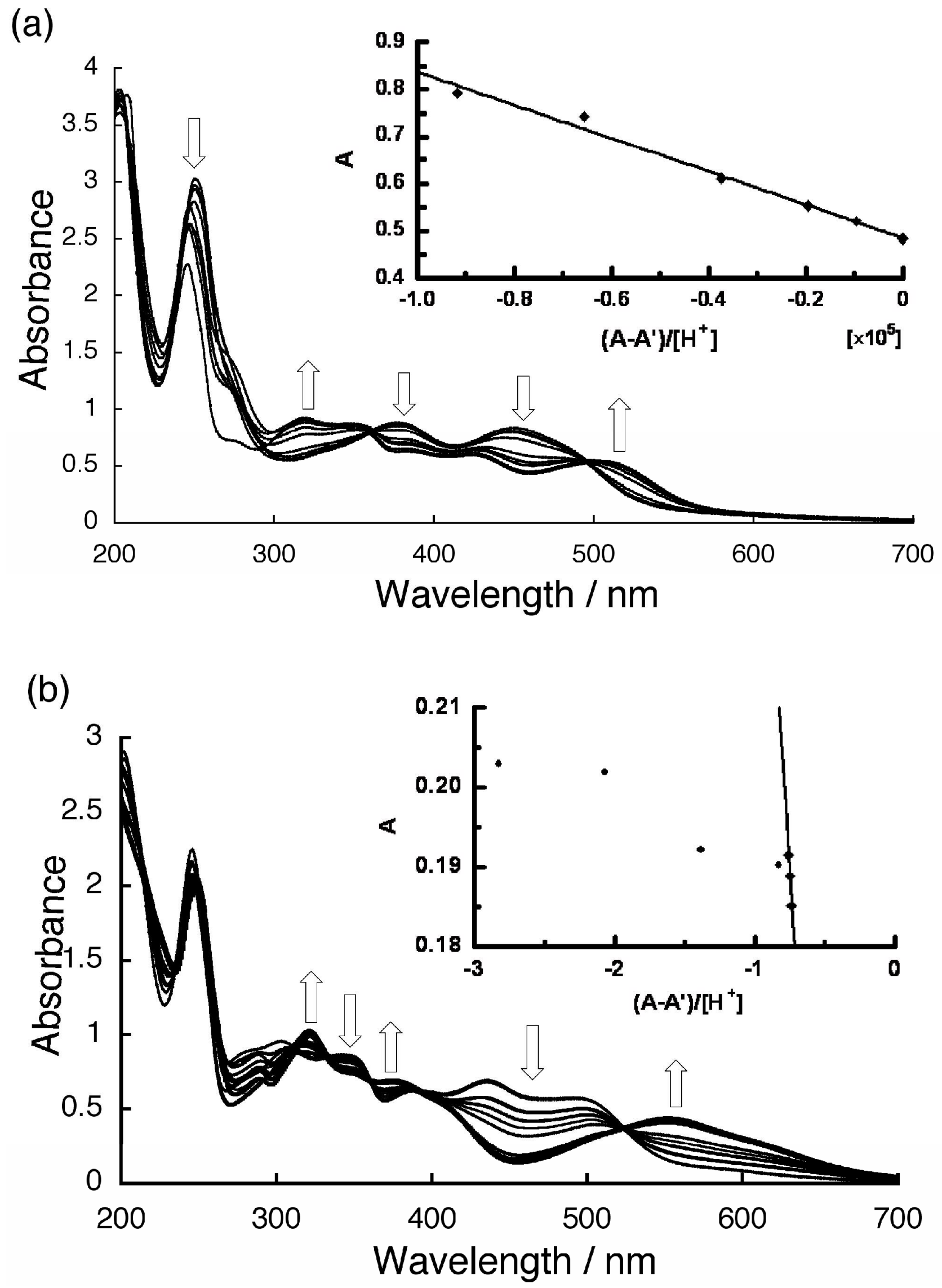

Figure S2. UV-vis spectral changes of $\mathbf{3}$ in aqueous Britton-Robinson buffer: (a) the first protonation step, (b) the second protonation step. Insets: plots of $A$ versus $\left(A-A^{\prime}\right) /\left[H^{+}\right]$. 
Table S1. Hyperfine coupling constant (in gauss) of $\mathrm{H}_{2} \mathrm{dmdmp}$ based on isotropic fermi contact couplings obtained by DFT calculations

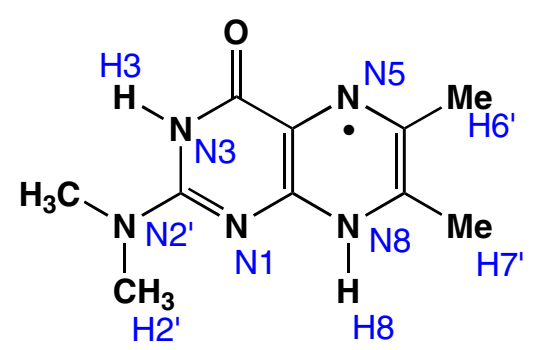

\begin{tabular}{lccccc}
\hline & exp & UB3LYP/6-31G(d) & UB3LYP/3-21G* $\begin{array}{c}\text { UB3LYP/6-31+G(d,p) } \\
\text { //UB3LYP/6-31G(d) }\end{array}$ & $\begin{array}{c}\text { UB3LYP/EPR-II } \\
\text { //UBYP/6-31G(d) }\end{array}$ \\
\hline $\mathrm{N} 1$ & 0 & 0.58 & 0.71 & 0.21 & 0.48 \\
$\mathrm{~N} 3$ & 0 & 0.56 & 0.70 & 0.46 & 0.42 \\
$\mathrm{~N} 5$ & 8.09 & 7.76 & 9.79 & 7.79 & 5.63 \\
$\mathrm{~N} 8$ & 4.99 & 3.40 & 4.62 & 3.38 & 2.78 \\
$\mathrm{~N} 2^{\prime}$ & 0 & 0.26 & 0.28 & 0.21 & 0.18 \\
$\mathrm{H} 2^{\prime}$ & 0 & 0.34 & 0.30 & 0.30 & 0.35 \\
$\mathrm{H} 3$ & 0 & 0.14 & 0.23 & 0.04 & 0.11 \\
$\mathrm{H} 6^{\prime}$ & 1.74 & 2.13 & 2.09 & 1.84 & 1.59 \\
$\mathrm{H}^{\prime}$ & 9.20 & 8.56 & 7.23 & 7.73 & 7.97 \\
$\mathrm{H} 8$ & 8.33 & 6.83 & 5.66 & 6.03 & 5.89 \\
& & & & & \\
\hline
\end{tabular}


Table S2. Hyperfine coupling constant (in gauss) of $\mathrm{H}_{2} \mathrm{dmp}$ based on isotropic fermi contact couplings obtained by DFT calculations

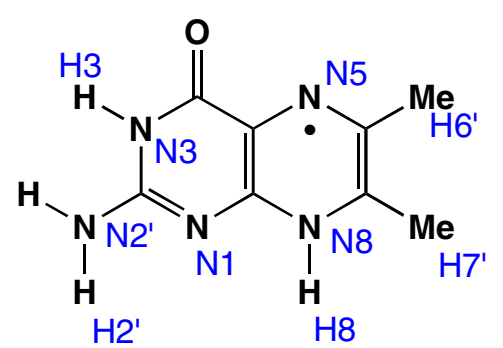

$\exp \quad$ UB3LYP/6-31G(d) UB3LYP/3-21G* UB3LYP/6-31+G(d,p) UB3LYP/EPR-II //UB3LYP/6-31G(d) //UB3LYP/6-31G(d)

\begin{tabular}{lcllll}
\hline N1 & 0 & 0.54 & 0.70 & 0.47 & 0.47 \\
N3 & 0 & 0.54 & 0.70 & 0.45 & 0.45 \\
N5 & 4.89 & 7.83 & 9.82 & 7.64 & 5.66 \\
N8 & 4.23 & 3.58 & 4.59 & 3.38 & 2.77 \\
N2' & 0 & 0.16 & 0.23 & 0.15 & 0.09 \\
$\mathrm{H}^{\prime}$ & 0 & 0.36 & 0.34 & 0.35 & 0.36 \\
$\mathrm{H} 3$ & 0 & 0.12 & 0.23 & 0.01 & 0.09 \\
$\mathrm{H} 6^{\prime}$ & 0.69 & 2.19 & 2.10 & 1.72 & 1.60 \\
$\mathrm{H} 7^{\prime}$ & 6.09 & 8.31 & 7.29 & 7.69 & 8.07 \\
$\mathrm{H} 8$ & 8.15 & 6.32 & 5.63 & 5.63 & 5.89 \\
\hline
\end{tabular}

